\title{
A METHOD OF REHABILITATING THE C6 TETRAPLEGIC HAND
}

\author{
By C. M. H. Meyer, DOT(PTa), OTR, R. D. Shrosbree, M.B., Ch.B. \\ and D. L. ABRAhams \\ Spinal Cord Injury Unit, Conradie Hospital, Pinelands, Cape, South Africa
}

\begin{abstract}
One of the important aspects of total rehabilitation of the C6 tetraplegic is the fitting and application of flexor-hinge hand orthoses. It has been proved that through the use of these orthoses the tetraplegic is able to maintain a high standard of independence in work and every day life activities.

Successful fitting is dependent on two major aspects: (a) accurate fitting; (b) functional training in the use of the orthosis. These two aspects are discussed in the paper. A case history of two tetraplegics is also given to illustrate the degree of functional independence achieved with flexor-hinge hand splints.
\end{abstract}

Key words: Cervical spine; Spinal cord injury; Tetraplegia; Orthosis.

\section{Introduction}

WoRKING in the field of rehabilitation of the spinal cord injured, presents many a challenge. Every patient presents a new and specific challenge. The tetraplegics more so than the paraplegics as the result of loss of active function of their upper extremities in addition to loss of function in the trunk and lower extremities.

It is through the use of hands that man performs a job satisfactorily, is productive, creative, and expresses feeling, emotion, affection, understanding, lives a useful and independent life, earns a living and is self supportive. The C6 tetraplegic is deprived of many of these functions because as Wynn Parry says, he has suffered loss of one of the 'most vital organs'.

It should therefore, be the main aim and object in rehabilitation to help the tetraplegic to meet some of the above challenges and be able to function at his maximum level of independence. The tetraplegic needs to feel that he can live a useful and productive life and be a contributing member of society. Then only will life be worthwhile living.

One of the 'tools' available to help tetraplegics to gain some degree of independence and use their hands functionally to live a purposeful life is through the use of flexor-hinge hand orthoses.

The orthosis most commonly used in South Africa and specifically at Conradie Hospital is the 'Engen' flexor-hinge hand splint (Fig. I). Some modification has been done to the original design of this orthosis and is presented in this paper.

\section{Description of the Splint}

The orthosis is made up of four basic parts: the wrist cuff, palmarpiece, finger piece and adjustable actuating rod.

The palmar piece or hand cuff is made of laminated plastic material using the vacuum moulding technique. It supports the palmar arch and thumb in a good functional position.

The finger piece is made of I8-gauge stainless steel $3 \mathrm{I} 6$ and is designed to hold 

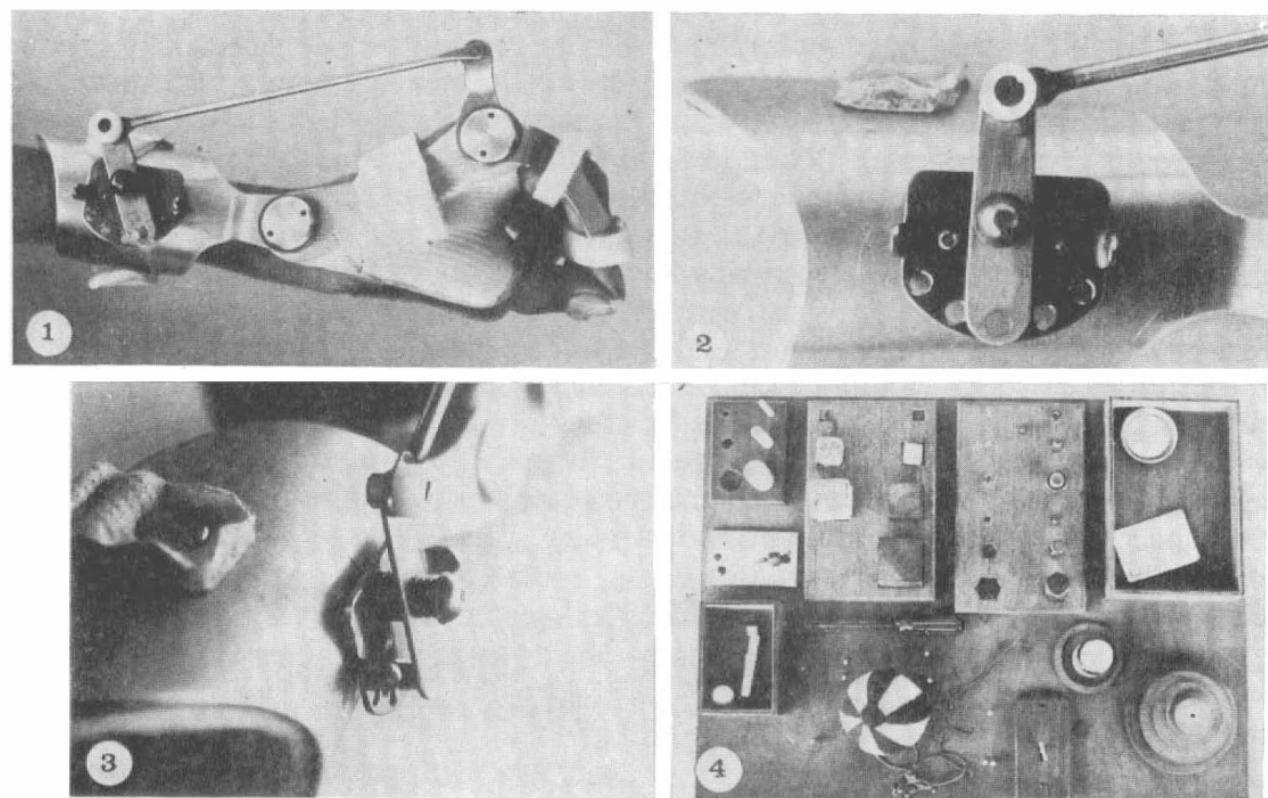

FIG. I

'Engen' flexor-hinge hand orthosis.

FIG. 2

Lateral view of actuating rod as designed at Conradie Hospital.

Fig. 3

Top view of actuating rod.

FIG. 4

A wooden board with objects of various sizes, designed for testing functional grip with the splint.

the index and middle finger in a functional position of approximately $50^{\circ}$ flexion at the P.I.P. joint and $30^{\circ}$ flexion at the D.I.P. joint.

The wrist cuff is made of $16 \mathrm{G}$ dural or equivalent half-hard aluminium alloy and is shaped according to the contour of the forearm proximal to the styloid process.

The actuating rod is made of stainless steel and is designed to bring about flexion of the finger M.P. joints by reciprocal action when the wrist is actively extended. At Conradie Hospital, a new mechanism was designed, in the BioMechanical Department, for adjusting the length of the actuating rod.

The proximal end of the actuating rod is attached to a spring-loaded lever system revolving around a $\frac{3}{16}$-inch $(5 \mathrm{~mm})$ steel stud which serves as an axis. A metal base plate, with $\frac{1}{8}$-inch $(3 \mathrm{~mm})$ holes drilled at regular intervals in a $\frac{5}{8}$-inch $(17.5 \mathrm{~mm})$ radius semicircle, is attached to the forearm piece. A pin at the end of the lever arm drops into the desired hole to establish the finger position. A coil spring is fitted under the head of the stud on which the lever revolves. The spring puts tension on the lever arm to hold the pin in position. Finger position is changed by applying pressure to the nylon disc on the proximal end of the actuating 
rod which in turn allows the position of the lever arm in the holes to be altered to the desired position (Figs 2 and 3).

Like all other flexor-hinge hand splints, this one also operates on the principle of tenodesis action whereby active wrist extension brings about flexion of the M.P. joints of the fingers. The index and middle finger are brought into opposition with the thumb to provide a three point pincer grip or finger prehension. The stronger the wrist extensor the stronger the grip will be. Therefore one of the aims of treatment prior to fitting the splint is to strengthen Extensor Carpi Radialis to its maximum. Wrist extension exercises are done through straightforward resisted wrist extension exercises, therapeutic apparatus (P.M.T.A.), activities specifically designed for wrist extension and general functional activities such as pushing the wheelchair, feeding, etc.

Another important aspect is to provide the patient with an opposition or short opponens splint immediately after admission so as to maintain the mobility of the web space between the thumb and index finger.

\section{Prerequisites for Fitting the Splint}

I. Good functional position of forearm, fingers, wrist and thumb, i.e. full range of pronation, $30^{\circ}$ wrist extension $90^{\circ}$ M.P. flexion, slight I.P. flexion, $70^{\circ}$ thumb abduction.

2. Normal web space of $35^{\circ}$ between thumb and index finger.

3. Full range of movement in wrist and M.P. joints.

4. Mobile or slightly flexed interphalangeal joints.

5. Pronation of forearm.

6. Strength of Ext. Carpi Radialis 4-according to Oxford Standard.

\section{Application}

Successful application of the orthosis depends on various aspects such as: age, education, team work, self-discipline, motivation, initiative and time of fitting.

The most important aspects to be considered for successful application are discussed more fully and these are (a) correct and precise fitting and (b) a dynamic training programme.

\section{The Importance of a Correct and Precise Fitting}

An ill-fitting splint can be as harmful as an ill fitting shoe. It causes pressure, pain, blisters, discomfort and possibly deformities. Apart from these physical problems, the worst is the frustration which the patient has to endure. The frustration caused by an ill fitting splint results in a negative attitude, depression or total resignation from co-operating in the rehabilitation programme. The tetraplegic has suffered enough physical and psychological trauma without causing him any more frustration by providing an ill fitting splint. Close co-operation between the therapist and the orthotist is essential so as to ensure a correct and precise fit.

\section{The Importance of a Dynamic Training Programme}

The basic purpose of the splint is to enable the tetraplegic to use his hands functionally. It is therefore the duty of the Occupational Therapist to provide an immediate opportunity for functional use in activity so that the tetraplegic can experience the success of the splint and understand its mechanics. The therapist should remember that the splint is a 'foreign object' and is not easily accepted by 
all persons as part of their everyday life. It is only through successful use in activity that the person can accept the splint as an essential 'tool' which he is prepared to wear and use daily. The patient must be involved in an activity programme from early on in his treatment so that he can experience the satisfaction of being able to accomplish something useful and be independent. The realisation of being able to do a job satisfactorily and independently will help the tetraplegic to enjoy the use of the splint and accept it as a part of him. The therapist has to prove to the patient through activity, that the splint is an 'essential tool' with which he can do a job better than without it.

Activities selected should relate to:

(I) personal activities such as feeding, brushing teeth, applying make-up;

(2) work related activities such as clerical or office work, (writing, typing, telephone handling), domestic work (sewing, cooking);

(3) social or recreational activities such as adapted games, music, hobbies, e.g. gardening, glass painting.

Unless patients are incomplete they are always fitted with bi-lateral flexor hinge hand splints. It has been proved that C6 tetraplegics achieve a higher degree of independence with two functional hands.

At Conradie Hospital a graded treatment programme was worked out in the Occupational Therapy Department to teach the patients how to use the orthosis correctly and understand its mechanics.

The training programme is divided into six different stages. The following is an outline of the training programme as quoted in Manual on Management of the upper extremity, by Malick and Meyer.

Stage I. Practice putting on and taking off the splint. Learn the adjustments of telescopic rod and how it determines the size of grip desired. Learn grasp and practice holding and releasing blocks of various sizes and shapes.

Stage 2. Practice grasp, hold and release of objects of various sizes and shapes related to activity. Suggested activities-block printing, mosaic, woodwork, block mosaics.

Stage 3. Practice grasp, hold and release at different heights. Suggested activities-practice in self-care skills (eating, drinking); work related skills (using a telephone, typewriter, dictaphone); recreational activities.

Stage 4. Practice pronation-supination movements. Suggested activitiesadvanced independence training (opening and closing screw tops such as toothpaste, make-up and bottle tops); work related jobs (putting paper into typewriter, adjusting roller, using a screwdriver, opening glue bottle); homemaking chores; avocational activities (adapted games).

Stage 5. Evaluation of functional movements. Use activites on a testing board for checking speed and dexterity of function (Fig. 4).

Stage 6. Work programme for future employment.

\section{Early Fitting}

Early fitting of the splint is another important aspect to be considered for successful rehabilitation. Reasons for early fitting are the follow!ng:

(a) Therapeutic: (i) strengthening of those hand and forearm muscles which can improve. The more active the muscle the sooner and the better strengthening occurs and (ii) maintaining functional position of the hand. 
(b) Creative participation-the splint facilitates participation in work orientated activities and everyday activities such as feeding, from early on in the rehabilitation programme. At Conradie Hospital patients are fitted with splints while still in bed.

(c) Acceptance-the patient has the opportunity of getting used to the splint and accepting it as part of his new existence from early on.

(d) Motivation-through successful participation in work orientated activities the patient's interest and motivation to work can be maintained.

The following two cases of C6 tetraplegics demonstrate the successful use and application of flexor-hinge hand splints.

Case No. I

Mrs G. M., a 43-year-old grossly overweight school-teacher, was involved in a motor vehicle accident sustaining a $\mathrm{C6} / 7$ cervical dislocation with bilateral facet interlocking and a C6 complete neurological lesion. The lesion was only partially reduced by means of Crutchfield tongs. She was discharged after I I months in hospital still a C6 complete neurological lesion and confined to a wheelchair. Two years later she was re-admitted and fitted with a pair of Engen splints. She became very adept in their use and was able to perform normal domestic tasks in the kitchen, e.g. cooking, etc. and also work as a school-teacher in a nursery school in the district from which she came.

\section{Case No. 2}

Mrs M. V. N., a 5I-year-old farmer's wife, was admitted to the Spinal Unit after a motor vehicle accident. She had sustained a C6/7 fracture dislocation of the cervical spine with bilateral facet interlocking. The neurological level was C6 complete. Crutchfield tongs were inserted and a manipulation under anaesthetic was successfully performed. She remained on traction on a pack bed for 12 weeks and was then allowed up in a wheelchair. She remained a C6 complete lesion and is wheelchair confined. Bilateral Engen splints were fitted early in her hospital stay and she became very adept at using them, and was discharged home after 9 months hospitalisation. She has returned to the farm and has continued with the work of a farmer's wife. Through the use of her splints she has been able to do activities which includes cooking, sewing, knitting and crocheting.

\section{Conclusion}

The 'Engen' flexor-hinge hand splint has become an essential 'tool' in the rehabilitation of the C6 tetraplegic at Conradie Hospital. Through the use of it, the tetraplegic achieves early independence, a high degree of independence and develops potential muscle power.

Acknowledgement. We wish to thank Dr D. F. Smith, Medical Superintendent, Conradie Hospital, for permission to publish this paper and the patients for their cooperation.

\section{RÉSUMÉ}

L'un des aspects importants de la réhabilitation totale des tétraplégqiues de niveau C6 est l'adaptation (et l'application) d'une orthose à charniére permettant la flexion. Il a été prouvés que grâce à l'emploi de ces orthoses la tétraplégique est capable de maintenir un haut niveau d'indépendance aussibien au cours de son travail que lors des activités journalières. 


\section{ZUSAMMANEFASSUNG}

Eine der wichtigsten Aspekte in der Rehabilitation des C6 Tetraplegiker ist die Anpassung und Gebrauch der 'flexor-hinge' Orthese.

Es hat sich bewiesen dass der C6 Tetraplegiker durch den Gebrauch der Orthese ein hohes Mass von Unabhängigkeit in der Arbeit und täglichen Selbstversorgung erreichen kann.

Zwei wichtige Faktoren zum erfolgreichen Gebrauch der Orthese sind: (a) akkurate Anpassung; (b) funktionelles Training im Gebrauch der Orthese. Diese beiden Faktoren werden beschrieben.

Zwei Fälle von Tetraplegikern, die den Grad der Unabhängigkeit durch den Gebrauch der Orthese zeigen, werden vorgetragen.

\section{REFERENCES}

Chusid, J. G. (1976). Correlative Neuroanatory and Functional Neurology, 16th edn., Lange Medical Publications, Los Altos, California.

ENGEL, W. H. et al. (I967). A functional splint for grasp driven by wrist extension. Archives of Physical Medicine and Rehabilitation. January.

ENGEN, T. J. (1970). Development of upper extremity orthotics and prosthetics. MarchJune.

MaLICK, M. H. \& MeYer, C. M. H. (1978). Manual on Management of the Quadriplegic upper extremity, Pittsburgh, Pennsylvania; Harmarville Rehabilitation Centre.

MeYer, C. M. H. (I975). The occupational therapist's application of dynamic splints in the rehabilitation of quadriplegics. South African fournal of Occupational Therapy, 5, No. I. 